\title{
Auditoria interna nas instituições públicas de ensino superior: Estudo empírico no contexto português
}

\section{Internal audit in public institutions of higher education: Empirical study in the Portuguese context}

\author{
Sandrina Machado \\ Instituto Superior Politécnico do Cávado e do Ave, Barcelos, Portugal \\ sandrinearaujomachado@gmail.com
}

\section{Sara Serra}

Escola Superior de Gestão do Instituto Superior Politécnico do Cávado e do Ave, Barcelos, Portugal sserra@ipca.pt

Patrícia Gomes

Instituto Superior de Contabilidade e Administração, Lisboa, Portugal

pgomes@ipca.pt

\begin{abstract}
Resumo
Este artigo visa estudar as funções do departamento de auditoria interna (AI) nas Instituições Públicas de Ensino Superior (IPES). A metodologia utilizada para desenvolver este trabalho foi o inquérito por questionário, submetido online, às IPES portuguesas. Como resultado foi obtida uma taxa de resposta de $43 \%$. Com este estudo concluímos que a maioria das IPES não tem departamento de Al apesar da elevada importância atribuída à sua existência. De facto, com este projeto verificámos que ainda existe um longo percurso a percorrer para que as IPES e os seus órgãos de gestão executem práticas efetivas que conduzam à implementação da Al no modelo de gestão e controlo. Apesar de algumas limitações do estudo empírico realizado, entendemos que o presente artigo contribui para enriquecer o conhecimento e a literatura académica nesta área, enfatizar a importância da Al, em particular no contexto do ensino superior, e sensibilizar a classe dos gestores públicos e políticos para o papel da Al no aumento dos níveis de transparência, eficiência, eficácia e qualidade dos serviços públicos.
\end{abstract}

Palavras-chave: auditoria interna; instituições públicas de ensino superior; departamento de auditoria interna; inquérito; Portugal.

\begin{abstract}
This paper aims to examine the role of internal audit department $(\mathrm{Al})$ in public Higher Education Institutions (HEIs). The methodology used to develop this study was an online survey of the Portuguese public HEls. As a result, a response rate of $43 \%$ was obtained. This study concludes that most HEls do not have an internal audit department although their usefulness is recognised. In fact, this study found that there is a long way to go for HEls and their management bodies to introduce and apply effective internal audit practices. Although it has some limitations, with this paper we hope to contribute to enrich the knowledge and the scant academic literature in this field, by emphasising the usefulness of Als, particularly in the HEI context, and by alerting policy makers and public managers to the role of $\mathrm{Al}$ in the increasing the levels of transparency, efficiency, effectiveness and quality of service delivered.
\end{abstract}

Keywords: internal audit; public Higher Education Institutions; internal audit department; survey; Portugal.

Dos Algarves: A Multidisciplinary e-Journal, 29 - 2017.

ISBN 2182-5580 ๑ ESGHT-University of the Algarve, Portugal.

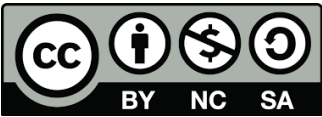

To cite this article: S. Machado, S. Serra e P. Gomes (2017). Auditoria interna nas instituições públicas de ensino superior: Estudo empirico no contexto português. Dos Algarves: A Multidisciplinary e-Journal, 29, 31-48. doi: 10.18089/DAMeJ.2017.29.2 


\section{Introdução}

$\mathrm{Na}$ atualidade, as IPES enfrentam muitos desafios, tais como a escassez de recursos, aumento dos custos operacionais, do tamanho e da complexidade institucional. Face ao exposto, para conseguir operar com os fundos disponíveis, os gestores são obrigados a avaliar a eficácia operacional e eficiência de suas instituições. Por estas razões, e considerando que a Al visa ajudar a entidade a alcançar os seus objetivos, bem como a avaliar e melhorar a eficácia da gestão dos processos de risco, controlo e governação, achamos relevante estudar a função dos departamentos de AI nas IPES. Deste modo, o objetivo deste trabalho é abordar a temática da AI nas IPES, analisando o departamento de Al e o perfil do auditor interno. Para o efeito, começamos por fazer um enquadramento teórico sobre a existência e posicionamento do departamento de $\mathrm{Al}$, abordando depois o perfil do auditor interno e os estudos empíricos realizados sobre a temática da AI nas IPES. De seguida, serão apresentados os resultados dos questionários ministrados às IPES. Espera-se, com este estudo, demonstrar o funcionamento dos departamentos de Al das IPES e sensibilizar os académicos e profissionais para a importância da Al.

\section{Departamento de auditoria interna}

As necessidades crescentes e, cada vez mais, exigentes do meio interno e externo fazem com que as organizações atinjam elevados níveis de complexidade organizacional e de informação. Por conseguinte, as:

[...] organizações públicas e privadas estão a aprimorar e modernizar os seus métodos de gestão, com o intuito de atingir os objetivos traçados e rentabilizar recursos para alcançar a meta da economia, eficiência e eficácia. Logo, cresce a necessidade de criar um departamento de auditoria interna, que possa assegurar o cumprimento das normas e o alcance dos objetivos requeridos pela gestão (Marçal \& Marques, 2011: 65).

Nesta linha de pensamento, Ma'ayan e Carmeli (2016) referem que o principal objetivo da Al é o apoio da alta administração, bem como ajudar as unidades auditadas a melhorar a ética, eficiência e eficácia das organizações.

A gestão de topo deve compreender que a Al não é uma forma de fiscalização e o seu caráter não é exclusivamente financeiro. A Al é, então, uma função que deve ser entendida como um instrumento ao serviço da gestão e estar consciente da rendibilidade e economicidade que um serviço de Al pode gerar na organização. Foi, precisamente, nesse contexto que a Al emergiu como principal aliada da gestão de topo, avaliando, recomendando e monitorizando os vários riscos com que se confrontavam os objetivos estratégicos por esta traçados (Almeida, 2005). Partilhando esta opinião, Groff, Di Pietra e Sitar (2016) aludem que, atualmente, a auditoria interna se centra na avaliação da gestão de riscos corporativos.

Todavia, existem alguns fatores que a organização deve ter em conta para a criação de um departamento de Al. Antes de mais, a gerência deve ponderar a viabilidade do referido departamento. Morais e Martins (2007) consideram que, no estudo da viabilidade, devem ser ponderados fatores como a dimensão e estrutura da entidade; o grau de organização da entidade, bem como a dispersão ou concentração de capital da entidade. Devemos considerar estes fatores, tendo em conta que a rendibilidade não é imediata nem facilmente quantificável 
nos primeiros anos deste serviço, necessitando, por isso, ser adotada uma atitude de consciencialização acerca dos seus efeitos (Marçal \& Marques, 2011).

Domingos Sequeira, presidente do Instituto Português de Auditoria Interna (IPAI), no artigo publicado por Sá (2008), no Jornal de Negócios, justifica que a gestão ainda não está muito envolvida e consciente da sua responsabilidade nesta matéria. A Al é considerada menor em algumas organizações, não por má-fé, mas, por falta de tradição, sensibilidade e, até, por uma questão cultural.

Quanto ao critério de economicidade deve ser efetuada uma pré-análise em relação custo/benefício. De acordo com Bilhim (2005), a única maneira de mudar as organizações é mudar a sua cultura, isto é, mudar a maneira de pensar, sentir e agir das organizações. Para tal, é necessário uma atitude de pré-adaptação, no sentido de ir preparando os responsáveis de todas as áreas para a aceitação deste serviço (Morais \& Martins, 2007). Os autores consideram, ainda, essencial, elaborar uma declaração de política da empresa sobre o departamento de Al, na qual se devem evidenciar os seus objetivos, o âmbito de atuação, as atribuições e competências, bem como o modo de funcionamento. Considera-se, assim, essencial que um departamento de Al consiga retratar a missão, a visão e os valores pelos quais se rege a empresa, para que seja mais fácil atingir os seus objetivos estratégicos.

Conhecida a importância que do departamento de Al, importa analisar a sua posição hierárquica, pelas funções que desempenha, exigindo-se total liberdade de atuação e independência relativamente a todos os outros serviços.

\section{Perfil do auditor interno}

Inicialmente, os auditores internos, chamados também de "controladores internos", pertenciam aos quadros da organização e tinham como único objetivo detetar erros e fraudes.

De acordo com Monteiro (1998), só aquando da criação do Institute of Internal Auditors (IIA), em 1941, é que se criaram condições para aumentar a independência dos auditores internos, definir melhor a sua função e desenvolver a profissão a nível mundial. Por conseguinte, a função dos auditores internos foi ampliada. Para além da validação dos registos contabilísticos, os auditores internos foram progressivamente alargando o seu âmbito de atuação, passando a assumir uma nova postura e redefinindo o conceito de auditor interno. No entanto, essa mudança não se fez de um momento para outro, pois com a alteração do âmbito de atuação, houve necessidade de efetuar alterações ao perfil do auditor interno. Para além das aptidões técnicas, os auditores internos necessitam de reunir um conjunto de novas aptidões e características pessoais e comportamentais. A propósito das características profissionais do auditor, Marques e Almeida (2004: 90) aludem que as normas destacam aspetos como a formação técnica, a independência e a responsabilidade profissional. Em Espanha, os "Princípios e Normas de Auditoria do Sector Público" exigem que o auditor possua as seguintes características: formação técnica e capacidade profissional; independência; diligência profissional; responsabilidade e segredo profissional. Em Portugal, o Tribunal de Contas, nos "Princípios aplicáveis aos auditores", inclui a independência, a competência e a diligência, em cujo âmbito se incluem as características exigidas pelas normas espanholas.

Segundo Skaerbaek (2009), a auditoria está constantemente sujeita a alterações. Por conseguinte, os auditores encetam esforços, constantes, para expandir as bases do conhecimento relativamente à auditoria. Face ao exposto, de acordo com Cashin (1982), os auditores internos, para além das características profissionais inerentes à profissão, devem ter 
capacidade de iniciativa, criatividade e curiosidade intelectual, poder de observação, saber ouvir, ter capacidade de perceção e assimilação rápida, possuir espírito analítico, ter facilidade de comunicação e de persuasão. Adicionalmente, o auditor deve ter capacidade para ver e analisar além das aparências, identificar insuficiências e problemas e compreender as suas causas e consequências, bem como ser capaz de encontrar soluções.

De acordo com um estudo realizado por Morais (2003), os auditores internos têm características, atributos e habilidades com domínio em várias áreas de conhecimento (requisitos do certificado de auditor interno), que lhes permite responder aos desafios e ajudar as organizações na adequada implementação da Al, com novas filosofias e ferramentas. Aliás, Endaya e Hanefah (2016) revelam que as características do auditor interno têm um impacto significativo sobre a eficácia da auditoria interna e o seu apoio à gestão.

\section{Estudos empíricos sobre a auditoria interna nas IPES}

Neste ponto são apresentados estudos empíricos internacionais sobre a Al nas IPES. Cumpre, no entanto, referir que são poucos os estudos realizados nesta área.

O estudo apresentado por Tato (1998), sobre a Al em universidades espanholas, propõe um marco de responsabilidade para o sistema público do ponto de vista da eficiência das universidades e politécnicos. Segundo este autor, em 1990, foi realizado um estudo, utilizando o Guia Peterson, que analisou várias instituições de ensino nos Estados Unidos, privadas (colégios) e públicas (universidades). Este estudo pretendeu conhecer as características do auditor interno, tendo-se concluído que a maioria dos auditores internos possuía formação em contabilidade, trabalhava a tempo integral para a entidade e reportava diretamente ao vicepresidente da área financeira. Além disso, as universidades realizavam igualmente auditoria externa anual, existindo, portanto, uma relação custo-benefício favorável aquando da existência de um auditor interno.

Quanto ao grupo de pessoas que beneficiavam com o trabalho dos auditores incluem-se, tanto nas universidades públicas como nas privadas, o presidente, as funções operacionais, o órgão de topo da universidade e os auditores externos.

Quando questionados sobre as razões de não possuir um auditor interno, as respostas apontam para a escassez de fundos; não perceber a necessidade de possuir um auditor interno; o facto de considerarem que outros colaboradores cumprem a mesma função; o facto dos auditores externos não recomendarem e, finalmente, não se percebe a relação custobenefício da sua existência.

Como conclusão do estudo, Tato (1998) apresenta, em termos de Al, uma proposta para as universidades espanholas. O autor propõe a institucionalização do departamento de Al, nas universidades públicas espanholas e internacionais, por um quadro jurídico. $O$ autor propõe criar comités de Al nas universidades públicas, de acordo com as disposições internacionais em vigor, como Committee of Sponsoring Organizations of the Treadway Commission (COSO) e Cadbury. O autor sugere, ainda, que a função de Al se reporte diretamente ao reitor da universidade ou ao conselho geral, não devendo nenhum nível hierárquico ter autoridade sobre ela.

Num estudo similar, realizado nos EUA, Rezaee, Elmore e Szendi (2001) reiteraram a importância da Al nas universidades. Os autores também incorporam o papel da Al na gestão e controlo da eficiência e eficácia das operações. Os resultados deste estudo destacam a 
importância, o papel e as responsabilidades da Al à luz das mudanças do ambiente das universidades.

Zakaria, Selvaraj e Zacaria (2006), num estudo às IPES da Malásia, referem a importância da função de Al como apoio à gestão das IPES. No referido estudo empírico foi aplicado um questionário a dezassete universidades públicas e quarenta e nove universidades privadas que compõem a totalidade do sistema de ensino superior da Malásia. Os resultados revelaram que $18,4 \%$ das universidades privadas e $88,2 \%$ das universidades públicas possuíam um departamento de Al. Apesar deste resultado, o estudo conclui que as universidades públicas e privadas têm a mesma perceção sobre o papel dos auditores internos e as áreas mais importantes da Al.

Mihret e Yismaw (2007) efetuaram um estudo de caso à maior instituição pública de ensino superior na Etiópia, com o móbil de analisar a qualidade da auditoria, o seu apoio à gestão, ao ambiente organizacional e se os atributos do auditado afetam a eficácia dos serviços de Al. Este estudo foi elaborado com base nos dados coletados por meio de questionários distribuídos aos funcionários do departamento de Al e uma entrevista realizada com o responsável do respetivo departamento. Os resultados revelaram que dos catorze auditores existentes no departamento de $\mathrm{Al}$, cinco são funcionários do quadro e os restantes são trabalhadores temporários. Desses auditores, dois possuem qualificações na área, oito possuem curso universitário e quatro cursos profissionais. A referida investigação concluiu, ainda, que a permanência média dos funcionários no departamento de Al é de cinco vírgula cinquenta e três anos.

Apesar do elevado número de colaboradores do departamento de $\mathrm{Al}$, os resultados revelaram que a Al necessita de melhorar em termos de planeamento, documentos de trabalho e no sistema de recomendações e de comunicação. Outro fator negativo apontado foi o facto dos profissionais do departamento de Al deterem poucas qualificações. Os resultados revelaram, ainda, que o departamento de Al reporta ao presidente, o que reforça o conceito de independência. Ainda assim, em geral, não é dada a devida atenção às recomendações da $\mathrm{Al}$ pois, embora os relatórios de auditoria sejam considerados adequadamente preparados, apresentam a informação de modo pouco consistente.

As conclusões do estudo destacam que a eficácia da Al é fortemente influenciada pela qualidade da mesma e pelo apoio à gestão, ao passo que o ambiente organizacional e as características do auditado não têm um forte impacto sobre a eficácia da auditoria.

Anos mais tarde, também, na Etiópia, FareedMastan, Gameda, Rajeswari e Muhammed (2015) desenvolveu uma pesquisa com o objetivo de avaliar a eficácia da Al na melhoria do desempenho organizacional da Universidade Wollo, usando a metodologia do questionário e entrevistas. O estudo revelou que a Al na Universidade Wollo tem um parco contributo na melhoria do desempenho organizacional, talvez pelos seus auditores internos não possuírem a experiência requerida.

O estudo de Christopher (2012) visa verificar até que ponto as funções de Al são adotadas nas universidades públicas australianas e quais são os fatores que influenciam a sua adoção. Para o efeito, foram realizadas entrevistas aos vice-reitores das universidades públicas australianas. Os nove vice-reitores entrevistados afirmaram que a função de Al é um elemento importante para a gestão da entidade, uma vez que dá feedback regular sobre a eficácia e eficiência de todos os seus processos. Perante este cenário, cinco entrevistados indicaram que as suas universidades têm departamento de Al de forma a satisfizer o papel teórico de apoio 
à gestão. $\mathrm{O}$ apoio à gestão, a existência de um comité de auditoria e um posicionamento adequado dentro da organização são os fatores que mais contribuem para a importância que é atribuída ao departamento de Al. Os restantes quatro entrevistados revelaram algumas consequências negativas na execução das funções de Al. Estas consequências negativas foram motivadas por uma série de fatores. O primeiro fator tem a ver com o ambiente organizacional. Em segundo lugar, a existência de pessoal não qualificado para assumir as responsabilidades do departamento de Al, motivada, essencialmente, pela dificuldade de captação de profissionais qualificados, dado que o sector privado consegue oferecer-lhes uma remuneração mais elevada. Esta situação levou as universidades a contratarem entidades externas para realizar toda, ou parte, da função de Al.

Todavia, a inconsistência na função de Al é sustentada por um problema mais vasto relacionado com a falta de regulamentação para o sector. Como não há obrigatoriedade legal para os auditores internos serem membros do IIA, não há forma de controlar o cumprimento obrigatório das suas diretrizes.

A investigação de Adetoso, Oladejo e Akesinro (2013) teve como objetivo verificar a eficácia do auditor interno no controlo de fraudes e outras irregularidades financeiras em universidades privadas do sudoeste na Nigéria. Os dados foram obtidos pela aplicação de um questionário. Os resultados mostram que os auditores internos são eficazes no controlo de fraudes e outras irregularidades financeiras e que os relatórios de auditoria foram relevantes na exposição dos diversos meios de fraudes financeiras. Todavia, o auditor interno só é eficaz em expor fraudes se a estrutura orgânica da universidade permitir que ele faça o seu trabalho. Embora chegasse a conclusões semelhantes, o estudo de Asiedu e Deffor (2017), realizado no Gana, concluiu o efeito da Al no controlo de fraudes depende do tamanho do departamento de Al e da sua independência. Assim, a adesão rigorosa e a implementação de regulamentos e leis, bem como a independência do departamento de Al, ajudarão a combater a fraude, essencialmente, a corrupção.

Os supracitados estudos foram corroborados pela investigação de Habib e Jalloh (2016), que aferiu que o controlo interno e a Al promovem uma melhoria contínua no sistema educacional nigeriano.

Arana (2013) desenvolveu, também, um estudo de caso sobre a Al nas universidades públicas de Espanha e do México. Para saber o estado atual da função de Al nas universidades públicas de Espanha e do México, o autor enviou questionários aos responsáveis do departamento de $\mathrm{Al}$, ou seu equivalente, e à gestão de topo ou a quem mais perto está da mesma. $\mathrm{O}$ autor conclui que, tanto as universidades públicas de Espanha, como as do México, têm a função de Al, mas a um nível médio de desenvolvimento. Nas universidades espanholas evidencia-se um desequilíbrio entre o perfil do responsável e as equipas de trabalho, e nas universidades mexicanas verifica-se um equilíbrio com alto risco de se perder.

Apesar de algumas diferenças individuais nos sistemas universitários, o resultado obtido mostra que, tanto nas universidades públicas espanholas como nas mexicanas, ainda não foi dada a devida importância às várias abordagens e atributos da Al moderna, como o estabelecimento do estatuto da Al, a apresentação adequada dos seus resultados, bem como a participação na gestão dos riscos e a ligação direta com a gestão de topo. Ainda assim, nas universidades públicas de Espanha e do México domina uma cultura de Al, enfatizando a função do controlo interno. Todavia, conclui-se que, em ambos os sistemas universitários, é 
necessário reajustar os processos relativamente à nomeação do responsável da $\mathrm{Al}$, para que haja uma perceção geral quanto à sua independência e apoio estratégico ao mais alto nível.

Também no contexto espanhol, Laviada, García e Arana (2014) realizaram um estudo para verificar se as universidades públicas espanholas têm, na sua estrutura organizacional, um departamento de Al e, em especial, a aplicabilidade do conceito moderno de Al. Neste caso, a modernidade é entendida como um atributo que garante transparência, colaboração e responsabilidade por parte da Al. Para analisar estas questões, o autor enviou, através da internet, um questionário a cinquenta universidades públicas espanholas. Dos vinte e nove questionários recebidos, quatro indicaram não possuir departamento de $\mathrm{Al}$, as restantes unidades assumiram a existência de departamento de Al. No entanto, algumas delas não responderam a todas as questões. Em suma, os resultados deste estudo indicaram que 0 departamento de Al está, sobretudo, sobre a alçada do gestor (42\%) e do reitor (33\%). Existe, em média, aproximadamente quatro pessoas por departamento de Al. As principais atividades auditadas são de controlo/intervenção (despesas, receitas e investimentos e todos os atos decorrentes, direitos e obrigações económicas), os orçamentos e atividades de recrutamento. Os autores verificaram, contudo, que existe uma forte dominância de Al nas universidades públicas espanholas que responderam ao estudo. Apesar das respostas estarem de acordo com o uso de técnicas e da legislação em vigor, tal não é suficiente para classificar o desempenho de um conceito de Al como moderno.

Ribeiro (2016) realizou um estudo sobre o papel da AI nas IPES em Portugal continental. Neste estudo concluiu-se que $49 \%$ das IPES não possuem departamento de Al, embora $97 \%$ destas entidades considere que a Al acrescenta valor à entidade. Na maioria das instituições (69\%), o departamento de Al depende do reitor (45\%) e do Conselho de Administração/Direção (24\%). Na maior parte das instituições o departamento de Al é constituído por mais do que duas pessoas.

Seguindo esta linha de investigação, no Brasil, Brito, Pimenta, Souza e Cruz (2016) realizaram um estudo através do envio de questionários a 422 servidores públicos integrantes das unidades de Al das 103 instituições federais de ensino brasileiras, tendo obtido uma taxa de resposta de 30,09\% (127 questionários respondidos). Os dados revelaram que a maioria dos auditores internos $(74,02 \%)$ possui curso de especialização, $22,05 \%$ possuem mestrado, 2,36\% possuem doutoramento e apenas $1,57 \%$ possui apenas o curso de graduação. A formação académica dos auditores internos centra-se na contabilidade (40,94\%), direito (31,50\%) e economia (14,17\%). Constatou-se, ainda, que a grande maioria dos respondentes $(86,61 \%)$ não possui qualquer certificação em Al. Quanto ao tempo de atuação na área de $\mathrm{Al}$, a maioria dos respondentes $(65,35 \%)$ atua há mais de três anos na $\mathrm{Al}$, sendo $42,52 \%$ de cinco a dez anos, $18,90 \%$ de três a cinco anos e 3,93\% acima de dez anos. Tal resultado permite afirmar que há grande oportunidade para investir na qualificação em Al, essencialmente, por meio de certificações internacionais, especialmente, aquelas que são promovidas pelo IIA.

\section{Hipóteses de investigação}

Este trabalho tem como objetivo analisar o funcionamento do departamento de AI nas IPES. Tal como nas anteriores investigações, será de esperar que quanto maior for a IPES, mais complexa será a sua estrutura e, portanto, maior será a probabilidade de possuir um departamento de Al. Face ao exposto, formularam-se as seguintes hipóteses de investigação: 
- $\quad \mathrm{H} 1$ - O tipo de estabelecimento de ensino (universidade ou politécnico) determina a existência de um departamento de Al.

- $\mathrm{H}_{2}$ - A existência de um departamento de Al está positivamente relacionada com a dimensão (total de alunos inscritos) da instituição.

Cumpre referir que as supracitadas hipóteses de investigação não foram criadas com base em nenhum estudo empírico concreto, dada a sua inexistência, mas com base no conhecimento adquirido no decurso desta pesquisa.

\section{A recolha e tratamento dos dados}

Tal como verificamos na revisão da literatura, a maioria dos estudos empíricos realizados sobre a AI nas IPES utilizaram a metodologia do inquérito por questionário. Face a esta constatação, bem como à abrangência geográfica da população e à maior facilidade na recolha das respostas, optamos, também, por utilizar o questionário. Por conseguinte, optou-se pela construção de um questionário online, enviado por e-mail, utilizando a ferramenta do Google: docs.google.com.

Na elaboração do questionário foi utilizada uma escala de medida às várias alternativas de resposta, de forma a possibilitar a sua análise por meio de técnicas estatísticas. Assim, para conjuntos de categorias de respostas qualitativamente diferentes e mutuamente exclusivas, aplicamos uma escala nominal do tipo Visual Analogue Scales (VAS), e para conjuntos de respostas alternativas, em que se estabelece uma relação de ordem entre elas, aplicamos uma escala ordinal, do tipo Likert (Cruz, 2004), com cinco categorias ("NI - Nada Importante", "PI - Pouco Importante", “I - Importante”, “Al - Alguma Importância” e “MI - Muito Importante").

Através do website da Direcção Geral do Ensino Superior, identificámos 35 IPES, que constituem o universo em estudo. $O$ inquérito foi enviado a todas estas instituições, tanto aos serviços centrais como aos Serviços de Ação Social (SAS) pois, na maioria dos casos, os SAS têm autonomia própria e podem ter um departamento de Al autónomo da restante instituição. Apenas uma instituição referiu que os SAS não têm autonomia em relação aos serviços centrais, logo não poderia responder ao questionário. Assim, foram enviados setenta questionários, tendo o período de recolha de dados mediado entre 24 de julho e 15 de outubro de 2014. Foram obtidas trinta e uma respostas, sendo trinta consideradas válidas, o que corresponde a uma taxa de resposta de $43 \%$.

Após validação da base de dados, efetuou-se o seu tratamento estatístico no software Statistical Package for the Social Sciences (SPSS), versão 20. O tratamento dos dados consistiu, essencialmente, numa análise univariada. Para efetuar a comparação entre grupos, utilizou-se o teste Mann-Whitney. Assim, se existir homogeneidade, as hipóteses de investigação serão testadas com base na amostra total, utilizando-se, para o efeito, o teste Qui-quadrado. No caso de uma não existir homogeneidade, será necessário realizar estes testes, também, para os dois grupos separadamente (universidades e institutos politécnicos). 


\section{Apresentação e discussão dos resultados}

A amostra deste estudo é constituída por trinta IPES, das quais onze são universidades e dezanove são politécnicos. A maioria das entidades que responderam ao questionário foram os SAS dos politécnicos (onze), seguindo-se os serviços centrais dos politécnicos (oito). As universidades aderiram menos ao questionário, havendo seis respostas por parte dos serviços centrais e cinco respostas dos SAS.

Tal como se pode ver na Tabela 1, quando questionados sobre a existência de um departamento de $\mathrm{Al}, 60 \%$ das IPES responderam que não possuem departamento de $\mathrm{Al}$. Embora a maioria das universidades e dos politécnicos não possuam departamento de Al, há maior disparidade nas universidades, pois $72,7 \%$ das mesmas não têm departamento de Al, enquanto nos politécnicos a percentagem é de $52,6 \%$.

Tabela 1. Existência de um departamento de Al

\begin{tabular}{|l|c|c|c|c|c|c|}
\cline { 2 - 7 } \multicolumn{1}{c|}{} & \multicolumn{2}{c|}{ Amostra Total } & \multicolumn{2}{c|}{ Universidades } & \multicolumn{2}{c|}{ Politécnicos } \\
\cline { 2 - 7 } \multicolumn{1}{c|}{} & Frequência & $\%$ & Frequência & $\%$ & Frequência & $\%$ \\
\hline Sim & 12 & 40,0 & 3 & 27,3 & 9 & 47,4 \\
\hline Não & 18 & 60,0 & 8 & 72,7 & 10 & 52,6 \\
\hline Total & 30 & 100,0 & 11 & 100,0 & 19 & 100,0 \\
\hline
\end{tabular}

Contrariamente ao que seria esperado, pelo facto das universidades serem de maior dimensão (alunos, funcionários, orçamento), supúnhamos que estas tivessem melhores procedimentos de $\mathrm{Al}$ do que os politécnicos. Comparando o presente estudo ao de Zakaria et al. (2006) e Laviada et al. (2014), verificamos que as IPES de Portugal ainda têm um longo caminho a percorrer. Nos estudos mencionados, a taxa de existência de Al nas instituições de ensino superior é bastante superior à nossa, Zakaria et al. (2006) aferiram que 88,2\% das universidades da Malásia têm um departamento de Al e Laviada et al. (2014) aferiram que a maioria das universidades espanholas também possui departamento de Al na sua estrutura organizacional.

Tal como havíamos referido na parte do enquadramento teórico, o auditor interno deve ocupar uma posição adequada no seio da instituição para que o seu trabalho não sofra pressões nem possa ser controlado por aqueles a quem a Al reporta, sendo conveniente que dependa da direção. De acordo com Paço (1997), a Al deve estar sobre a alçada do órgão de gestão hierarquicamente mais elevado na organização. A dependência para com este órgão é normalmente respeitada na maioria das organizações em que está implementada.

O estudo de Tato (1998) sobre a Al nas universidades espanholas sugere a criação de comités de Al nas universidades públicas, de acordo com as disposições internacionais, mas também propõe que a Al reporte diretamente ao reitor/presidente da universidade ou ao conselho geral e sem que qualquer outro nível hierárquico tenha autoridade nela. De acordo com Badara e Saidin (2013), deve existir uma estreita ligação entre a gestão e a Al de forma a responder às necessidades do comité de auditoria e não defraudar as expetativas.

Corroborando a revisão da literatura, os resultados revelaram que as instituições que possuem departamento de Al reportam maioritariamente ao presidente $(33,3 \%)$ e ao conselho de gestão (33,3\%). Logo de seguida, com $25 \%$ de respostas, foi assinalada a opção "Outra" 
(Vice-reitor e ao Círculo de Progresso). Das universidades que possuem departamento de Al, apenas uma $(33,33 \%)$ reporta ao presidente, as restantes duas assinalaram a opção "Outra", reportando ao administrador e ao vice-reitor (Tabela 2). Os institutos politécnicos reportam maioritariamente ao conselho de gestão $(44,4 \%)$ e ao presidente $(33,3 \%)$.

Tabela 2. A quem reporta o departamento de Al

\begin{tabular}{|l|c|c|c|c|c|c|}
\cline { 2 - 7 } \multicolumn{1}{c|}{} & \multicolumn{2}{c|}{ Amostra Total } & \multicolumn{2}{c|}{ Universidades } & \multicolumn{2}{c|}{ Politécnicos } \\
\cline { 2 - 7 } \multicolumn{1}{c|}{} & Frequência & $\%$ & Frequência & $\%$ & Frequência & $\%$ \\
\hline Presidente & 4 & 33,3 & 1 & 33,3 & 3 & 33,3 \\
\hline Conselho de Gestão & 4 & 33,3 & 0 & 0,0 & 4 & 44,4 \\
\hline Comité de Auditoria & 1 & 8,3 & 0 & 0,0 & 1 & 11,1 \\
\hline Outra & 3 & 25,0 & 2 & 66,7 & 1 & 11,1 \\
\hline Total & 12 & 100,0 & 3 & 100,0 & 9 & 100,0 \\
\hline
\end{tabular}

As instituições que ainda não possuem departamento de Al foram questionadas sobre a intenção de o criar e, em caso afirmativo, qual a data previsível. Os resultados demonstraram que está nos planos de 22,2\% dessas instituições criar um departamento de Al. Todavia, outros $22,2 \%$ dizem que não pretendem criar o departamento e mais de metade $(55,6 \%)$ não sabe.

Mais de metade das universidades que não têm departamento de Al não sabe se a sua instituição o irá implementar (62,5\%). Além disso, $25 \%$ afirma que não o pretende implementar. Apenas uma universidade pretende implementar um departamento de $\mathrm{Al}$, até ao final do ano.

Metade dos politécnicos que não têm departamento de Al na sua instituição não sabe se a mesma tem intenção de o implementar, 20\% afiança que não o pretende implementar e 30\% garante que sim, mas não a curto prazo (duas instituições indicaram que será daqui a dois anos e outra indicou que só depois de três anos).

Perante os dados obtidos, concluímos que a gestão, ainda, não está muito motivada para a Al. Segundo Sá (2008), citando o vice-presidente do IPAI, isto deve-se, sobretudo, a uma questão cultural e de falta de tradição.

Com a submissão do questionário, procuraram-se identificar os motivos das instituições não possuírem departamento de AI. Na Tabela 3, podemos verificar que quase todos os fatores assinalados contribuem para a inexistência de um departamento de Al. Todavia, os que mais se destacam são a falta de meios humanos com formação adequada e de meios técnicos adequados. A reduzida autonomia financeira é, de todos os fatores, considerada o menos relevante para justificar a inexistência do departamento de Al. 
Tabela 3. Fatores que contribuem para a inexistência de um departamento de Al (Amostra total)

\begin{tabular}{|c|c|c|c|c|c|c|c|c|c|c|c|c|}
\hline & \multicolumn{2}{|c|}{ Nenhuma } & \multicolumn{2}{|c|}{ Reduzida } & \multicolumn{2}{|c|}{ Alguma } & \multicolumn{2}{|c|}{ Bastante } & \multicolumn{2}{|c|}{ Muita } & \multicolumn{2}{|c|}{$\begin{array}{l}\text { Não } \\
\text { responde }\end{array}$} \\
\hline & $\mathrm{Fr}$ & $\%$ & $\mathrm{Fr}$ & $\%$ & $\mathrm{Fr}$ & $\%$ & $\mathrm{Fr}$ & $\%$ & $\mathrm{Fr}$ & $\%$ & $\mathrm{Fr}$ & $\%$ \\
\hline $\begin{array}{l}\text { Importância da } \\
\text { informação para a } \\
\text { gestão }\end{array}$ & 6 & 33,3 & 2 & 11,1 & 7 & 38,8 & 0 & 0,0 & 0 & 0,0 & 3 & 16,6 \\
\hline $\begin{array}{l}\text { Não existe imposição } \\
\text { legal }\end{array}$ & 3 & 16,6 & 1 & 5,5 & 6 & 33,3 & 5 & 27,7 & 1 & 5,5 & 2 & 11,1 \\
\hline $\begin{array}{l}\text { Falta de formação } \\
\text { adequada dos meios } \\
\text { humanos }\end{array}$ & 1 & 5,5 & 2 & 11,1 & 4 & 22,1 & 2 & 11,1 & 6 & 33,3 & 3 & 16,6 \\
\hline $\begin{array}{l}\text { Falta de meios } \\
\text { técnicos }\end{array}$ & 3 & 16,6 & 1 & 5,5 & 4 & 22,1 & 2 & 11,1 & 5 & 27,7 & 3 & 16,6 \\
\hline $\begin{array}{l}\text { Falta de envolvimento } \\
\text { dos gestores de topo }\end{array}$ & 2 & 11,1 & 3 & 16,6 & 4 & 22,1 & 5 & 27,7 & 1 & 5,5 & 3 & 16,6 \\
\hline $\begin{array}{l}\text { Falta de vontade } \\
\text { política }\end{array}$ & 4 & 22,1 & 3 & 16,6 & 5 & 27,7 & 2 & 11,1 & 1 & 5,5 & 3 & 16,6 \\
\hline $\begin{array}{l}\text { Dificuldades } \\
\text { financeiras }\end{array}$ & 0 & 0,0 & 5 & 27,7 & 3 & 16,6 & 5 & 27,7 & 2 & 11,1 & 3 & 16,6 \\
\hline $\begin{array}{l}\text { Falta de sistemas de } \\
\text { informação } \\
\text { adequados }\end{array}$ & 1 & 5,5 & 2 & 11,1 & 9 & 50,0 & 1 & 5,5 & 1 & 5,5 & 4 & 22,1 \\
\hline $\begin{array}{l}\text { Reduzida autonomia } \\
\text { financeira }\end{array}$ & 9 & 50,0 & 4 & 22,2 & 2 & 11,1 & 0 & 0,0 & 0 & 0,0 & 3 & 16,6 \\
\hline
\end{tabular}

Na Tabela 4 podemos verificar que existem, em média, nove pessoas a trabalhar no departamento de Al. No entanto, este número é influenciado por um instituto politécnico que, tanto nos serviços centrais como nos SAS tem trinta e oito funcionários. Excetuando esta situação, o número máximo de pessoas a trabalhar no departamento de Al é três, sendo o mais comum ter apenas uma pessoa. Estes resultados estão próximos dos do estudo de Laviada et al. (2014), que revelou que nas IPES de Espanha existem, em média, três virgula nove pessoas no departamento de Al. 
Tabela 4. Número de pessoas que trabalham no departamento de Al

\begin{tabular}{|l|c|c|c|c|c|c|}
\cline { 2 - 7 } \multicolumn{1}{c|}{} & \multicolumn{2}{c|}{ Amostra Total } & \multicolumn{2}{c|}{ Universidades } & \multicolumn{2}{c|}{ Inst. Politécnicos } \\
\cline { 2 - 7 } \multicolumn{1}{c|}{} & Frequência & $\%$ & Frequência & $\%$ & Frequência & $\%$ \\
\hline 1 & 5 & 41,6 & 0 & 0,0 & 5 & 55,6 \\
\hline 2 & 2 & 16,6 & 1 & 33,3 & 1 & 11,1 \\
\hline 3 & 1 & 8,3 & 0 & 0,0 & 1 & 11,1 \\
\hline 38 & 2 & 16,6 & 0 & 0,0 & 2 & 22,2 \\
\hline Total & 10 & 83,1 & 1 & 33,3 & 9 & 100,0 \\
\hline Náo responde & 2 & 16,6 & 2 & 66,6 & 0 & 0,0 \\
\hline Total & 12 & 100,0 & 3 & 100,0 & 9 & 100,0 \\
\hline
\end{tabular}

No presente estudo podemos, ainda, concluir que as pessoas que trabalham no departamento de Al possuem formação superior nas áreas de gestão, auditoria, contabilidade e economia, apresentando, em alguns casos, pessoas com mais do que uma formação superior (Tabela 5). Além disso, existem mais colaboradores do que responsáveis a terem formação em auditoria. Conforme mencionado por Marques e Almeida (2004), a caraterística que mais se destaca nos auditores internos é a sua formação técnica. Nesta linha de pensamento Christopher (2012) alude que a existência de pessoal não qualificado para assumir as responsabilidades do departamento pode levar a consequências negativas no departamento de Al.

Tabela 5. Área de formação dos recursos humanos do departamento de Al (Amostra total)

\begin{tabular}{|l|c|c|c|c|c|}
\cline { 2 - 6 } \multicolumn{1}{c|}{} & Auditoria & Contabilidade & Gestão & Economia & Outra \\
\hline Responsável & 2 & 3 & 4 & 2 & 1 \\
\hline Colaboradores & 5 & 1 & 2 & 1 & 7 \\
\hline Não responde & 2 & 2 & 2 & 5 & 3 \\
\hline
\end{tabular}

Os responsáveis do departamento de $\mathrm{Al}$ das universidades têm formação em contabilidade $(n=2)$ e em gestão $(n=1)$ e os colaboradores têm formação superior em auditoria ou outra formação (Tabela 6).

Tabela 6. Área de formação dos recursos humanos do departamento de Al - Universidades

\begin{tabular}{|l|c|c|c|c|c|}
\cline { 2 - 5 } \multicolumn{1}{c|}{} & Auditoria & Contabilidade & Gestão & Economia & Outra \\
\hline Responsável & 0 & 2 & 1 & 0 & 0 \\
\hline Colaboradores & 1 & 0 & 0 & 0 & 1 \\
\hline Não responde & 1 & 1 & 1 & 2 & 1 \\
\hline
\end{tabular}


A maioria dos responsáveis e os colaboradores do departamento de Al dos politécnicos não têm formação na área de auditoria (Tabela 7). Podemos, então, concluir que, sobretudo, os colaboradores do departamento de Al não estarão tão preparados para o exercício da sua função.

Tabela 7. Área de formação dos recursos humanos do departamento de Al - Politécnicos

\begin{tabular}{|l|c|c|c|c|c|}
\cline { 2 - 6 } \multicolumn{1}{c|}{} & Auditoria & Contabilidade & Gestão & Economia & Outra \\
\hline Responsável & 2 & 1 & 3 & 2 & 1 \\
\hline Colaboradores & 4 & 1 & 2 & 1 & 6 \\
\hline Não responde & 1 & 1 & 1 & 3 & 2 \\
\hline
\end{tabular}

Para desempenhar as suas funções, os auditores internos necessitam de mais do que aptidões técnicas, necessitam de reunir um conjunto de características pessoais e comportamentais. Segundo Marques e Almeida (2004), das características profissionais do auditor destacam-se, para além dos aspetos como a sua formação técnica, a independência e a responsabilidade profissional. Em Espanha, as normas que regem a auditoria no sector público exigem do auditor as seguintes características: formação técnica e capacidade profissional; independência; diligência profissional; responsabilidade e segredo profissional.

Quanto à importância atribuída às características que um auditor interno deve possuir para um adequado exercício das suas funções, conforme a Tabela 8, as instituições respondentes consideram que a integridade (77,8\%), a independência (63,3\%) e a confidencialidade (60\%) são as mais importantes. As características de caráter profissional, tal como as habilitações e experiência profissional, foram consideradas como características com menos importância para o bom desempenho do auditor interno mas, ainda assim, importantes. É dada a mesma importância pelas universidades a estas três características, acrescentado o zelo com a mesma percentagem que a independência e a confidencialidade. Como podemos atestar, os politécnicos dão maior importância às habilitações profissionais, integridade e confidencialidade.

Como verificamos na revisão da literatura, deve ser exigido aos auditores internos um comportamento que exceda o padrão razoável, no campo da ética e da integridade. Para além de uma ética profissional, deve, sobretudo, existir uma ética pessoal. Valores como a independência, como já referido anteriormente, mas também a integridade devem estar incutidos no auditor interno e devem, igualmente, ser cultivados e fazer parte da política da organização de modo que lhes sejam efetivamente reconhecidos. Por tudo isto, sugerimos a existência de um estatuto para o departamento de Al e para o próprio auditor interno (código ética), onde se encontram definidos os objetivos, autoridade e responsabilidade do mesmo. 
Tabela 8. Características do auditor interno (Amostra total)

\begin{tabular}{|c|c|c|c|c|c|c|c|c|c|c|c|c|}
\cline { 2 - 12 } & \multicolumn{2}{|c|}{ Independência } & \multicolumn{2}{c|}{ Zelo } & \multicolumn{2}{c|}{$\begin{array}{c}\text { Habilitações } \\
\text { Profissionais }\end{array}$} & \multicolumn{2}{c|}{ Integridade } & \multicolumn{2}{c|}{$\begin{array}{c}\text { Confiden- } \\
\text { cialidade }\end{array}$} & \multicolumn{2}{c|}{$\begin{array}{c}\text { Experiência } \\
\text { profissional }\end{array}$} \\
\cline { 2 - 13 } & Freq & $\%$ & Freq & $\%$ & Freq & $\%$ & Freq & $\%$ & Freq & $\%$ & Freq & $\%$ \\
\hline NI & 0 & 0,0 & 0 & 0,0 & 0 & 0,0 & 0 & 0,0 & 0 & 0,0 & 0 & 0,0 \\
\hline PI & 0 & 0,0 & 0 & 0,0 & 0 & 00,0 & 0 & 0,0 & 0 & 0,0 & 0 & 0,0 \\
\hline I & 1 & 3,3 & 1 & 3,3 & 4 & 13,3 & 0 & 0,0 & 0 & 0,0 & 2 & 6,7 \\
\hline Al & 6 & 20 & 9 & 30 & 13 & 43,3 & 6 & 22,2 & 9 & 30 & 14 & 46,7 \\
\hline MI & 19 & 63,3 & 17 & 56,7 & 10 & 33,3 & 21 & 77,8 & 18 & 60 & 11 & 36,7 \\
\hline NR & 4 & 13,3 & 3 & 10,0 & 3 & 10,0 & 3 & 10,0 & 3 & 10,0 & 3 & 10,0 \\
\hline Total & 30 & 100,0 & 30 & 100,0 & 30 & 100,0 & 30 & 100,0 & 30 & 100,0 & 30 & 100,0 \\
\hline
\end{tabular}

Onde: NI - Nada Importante; PI - Pouco Importante; I - Importante, Al - Alguma Importância e MI - Muito Importante; NR-Não respondeu

Para testar as hipóteses de investigação formuladas, calculamos o teste do Qui-Quadrado. Relativamente à $\mathrm{H} 1$ - $\mathrm{O}$ tipo de estabelecimento de ensino (universidade ou politécnico) determina a existência de um departamento de Al, a Tabela 9 apresenta o valor do teste do QuiQuadrado de 2,693 com um nível de significância de 0,441 e com 3 graus de liberdade. Estes resultados indiciam que as variáveis não estão relacionadas, não se rejeitando a hipótese nula, ou seja, não há relação entre o tipo de instituição e a existência de um departamento de Al. Este resultado já seria de esperar, dado que o teste Mann-Whitney revelou comportamentos semelhantes entre universidades e politécnicos.

Tabela 9. Teste Qui-quadrado - Existência de departamento de Al/Tipo de Instituição

\begin{tabular}{|c|c|c|c|}
\cline { 2 - 4 } \multicolumn{1}{c|}{} & Valor & $\begin{array}{c}\text { Grau de liberdade } \\
\text { (gdl) }\end{array}$ & $\begin{array}{c}\text { Nível de } \\
\text { significância }\end{array}$ \\
\hline Chi-Square & 2,693 & 3 &, 441 \\
\hline
\end{tabular}

A segunda hipótese de investigação ( $\mathrm{H}_{2}$ - A existência de um departamento de Al está positivamente relacionada com a dimensão (total de alunos inscritos) da instituição) relaciona a existência do departamento de Al com o número de alunos inscritos nas IPES. O teste QuiQuadrado está associado à hipótese nula $(\mathrm{Ho})$ de que as variáveis são independentes uma da outra. Conforme verificamos na Tabela 10, o teste assume o valor de 6,019, a um nível de significância de 0,198 com 4 graus de liberdade (gdl), pelo que não há relação entre as duas variáveis. Não se rejeita a hipótese nula, ou seja, conclui-se que o facto de existir Al e o número de alunos da IPES não são dependentes ao nível da significância estabelecida. 
Tabela 10. Teste Qui-quadrado - Departamento de Al/N. ${ }^{\circ}$ Alunos

\begin{tabular}{|c|c|c|c|c|c|c|c|c|c|}
\cline { 2 - 8 } \multicolumn{1}{|c|}{} & \multicolumn{4}{c|}{ Amostra Total } & \multicolumn{3}{c|}{ Universidades } & \multicolumn{3}{c|}{ Politécnicos } \\
\cline { 2 - 8 } & Valor & $\begin{array}{c}\text { Grau de } \\
\text { Liberdade } \\
\text { (gdl) }\end{array}$ & $\begin{array}{c}\text { Nível de } \\
\text { significância }\end{array}$ & Valor & $\begin{array}{c}\text { Grau de } \\
\text { Liberdade } \\
\text { (gdl) }\end{array}$ & $\begin{array}{c}\text { Nível de } \\
\text { significância }\end{array}$ & $\begin{array}{c}\text { Grau de } \\
\text { Vaberdade } \\
\text { (gdl) }\end{array}$ & $\begin{array}{c}\text { Nível de } \\
\text { significância }\end{array}$ \\
\hline Chi-Square & 6,019 & 4 &, 198 & 4,278 & 3 &, 233 & 2,846 & 3 &, 416 \\
\hline
\end{tabular}

De acordo com o Teste Mann-Whitney, a variável "número de alunos inscritos na instituição" não é homogénea para os dois grupos em estudo, logo, é necessário testar esta hipótese separadamente para as universidades e para os politécnicos. No entanto, como aferimos na tabela anterior, chegamos à mesma conclusão, isto é, não existe relação entre ambas as variáveis para os dois grupos.

\section{Conclusão}

O programa de reformas efetuado pela Administração Pública, em vários países, teve como resultado uma nova postura perante o cidadão, conhecida como New Public Management e é neste sentido que a prática regular de auditoria, interna e externa, no sector público é, cada vez mais, uma realidade. Tal como noutros organismos da Administração Pública, nas IPES, o papel dos gestores públicos é agora de assunção de maior responsabilidade, devendo gerir-se os recursos públicos de forma económica, eficiente e eficaz. Neste contexto, a Al tem sido impulsionada e reconhecida como uma função de valor acrescentado para a entidade.

Face a esta realidade, este trabalho visa analisar a função do departamento de Al nas IPES. Para o efeito, foi elaborado um questionário, ministrado online. A taxa de resposta foi de $43 \%$ e permitiu chegar aos seguintes resultados.

A maioria dos respondentes foram os politécnicos, nomeadamente os SAS. Por este motivo, a generalidade dos respondentes foram instituições de pequena dimensão, considerando o número de alunos.

Constatamos que grande parte das IPES respondentes não possui um departamento de Al na sua estrutura organizacional e não sabe se está nos planos da instituição criar um. $O$ principal fator para justificar a inexistência de um departamento de Al nestas entidades foi a falta de meios humanos com formação adequada e de meios técnicos. Ainda assim, todos os fatores colocados no questionário foram considerados pertinentes para justificar a necessidade da criação de um departamento de Al, destacando-se a importância da informação que a Al dá à gestão, o envolvimento da gestão de topo e a vontade política.

Verificamos que nas IPES que têm departamento de Al existem, em média, nove pessoas a trabalhar no mesmo, mas tal como justificámos na análise e discussão de resultados, consideramos que este resultado está influenciado por um politécnico que tanto nos serviços centrais como nos SAS indicou ter trinta e oito funcionários. Excetuando estas duas situações, o mais comum é ter apenas uma pessoa a trabalhar no departamento de Al. Tal como abordado na revisão da literatura, verificamos através do questionário que as características consideradas essenciais para o perfil do auditor interno são a integridade, a independência e a confidencialidade. Corroborando, igualmente, a revisão da literatura, aferiu-se que as IPES que 
têm um departamento de Al reportam maioritariamente ao presidente e ao conselho de gestão.

A melhoria dos processos e operações, bem como a avaliação e melhoraria da eficácia dos processos de controlo e gestão do risco foram os objetivos mais atribuídos à Al.

Em suma, e ao contrário do esperado, constatamos que os politécnicos têm melhores práticas e procedimentos de Al do que as universidades.

Relativamente às hipóteses formuladas, verificamos que a existência de um departamento de Al não está relacionada com o tipo de instituição, nem com a dimensão (número de alunos).

Seja qual for a natureza de um trabalho, este está sempre sujeito a limitações que o condicionam e podem afetar os seus resultados. Na revisão da literatura foram detetadas carências de estudos, especialmente empíricos, sobre o papel da Al, particularmente em organizações do sector público, especificamente no ambiente de instituições de ensino superior. Esta situação constitui uma desvantagem para entender a evolução concetual e prática da $\mathrm{Al}$, não promovendo a cultura da $\mathrm{Al}$ no campo em questão. O facto de não existir, em Portugal, estudos que comparem universidades com politécnicos foi outra da dificuldade com que nos deparamos, pois não existe base de comparação.

Apesar das limitações apontadas, com este estudo verificámos que ainda existe um longo percurso a percorrer para que as IPES e os seus órgãos de gestão estejam sensibilizados para a importância da Al. Assim, esperamos que, com o presente artigo, tenhamos contribuído para enriquecer um pouco mais a literatura académica, apresentar a importância da Al e os benefícios associados a esta, para que possa despertar o interesse para a sua implementação.

Esta investigação não teve a pretensão de esgotar o assunto pois, ainda há muito que pesquisar e estudar a respeito da convergência da Al e do seu contributo na análise da economia, eficiência e eficácia das operações da organização, cumprindo, assim, a sua missão como função de apoio à gestão.

\section{Referências bibliográficas}

Adetoso, J., Oladejo, K. \& Akesinro, A. (2013). Effectiveness of internal auditor in controlling fraud and other financial irregularities in private universities in south-west, Nigeria. Research Journal of Finance and Accounting, 4 (13), 106-110.

Almeida, B. (2005). Auditoria e sociedade: Diferenças de expectativas. Lisboa: Publisher Team.

Arana C. (2013). La auditoría interna en las universidades públicas de España y México (Tese de doutoramento não publicada). Universidad de Cantabria, Santander, Espanha.

Asiedu, K. \& Deffor, E. (2017). Fighting corruption by means of effective internal audit function: Evidence from the Ghanaian public sector. International Journal of Auditing, 21, 82-99. doi: 10.1111/ijau.12082

Badara, M. \& Saidin, S. (2013). The relationship between audit experience and internal audit effectiveness in the public sector organizations. International Journal of Academic Research in Accounting, Finance and Management Sciences, 3 (3), 329-339. doi: 10.6007/IJARAFMS/v3-i3/224

Bilhim, J. (2005). Teoria organizacional: Estruturas e pessoas. Lisboa: Instituto Superior de Ciências Sociais e Políticas.

Brito, G., Pimenta, D., Souza, E. \& Cruz, A. (2016). Benefícios e desafios da auditoria baseada em risco em Instituições Federais de Ensino. Comunicação apresentada no XVI Colóquio Internacional de Gestión Universitaria, Perú.

Cashin, J. (1982). Handbook for auditors (2. ed.). New York: McGraw Hill Higher Education.

Christopher, J. (2012). The adoption of internal audit as a governance control mechanism in Australian public universities - Views from the CEOs. Journal of Higher Education Policy and Management, 34 (5), 529-541. doi: 10.1080/1360080X.2012.716001 
Cruz, V. (2004). Método de Likert o de las tasaciones sumadas. Bogotá: Departamento de Psicología, Universidad de los Andes.

Endaya, K. \& Hanefah, M. (2016). Internal auditor characteristics, internal audit effectiveness, and moderating effect of senior management. Journal of Economic and Administrative Sciences, 32 (2), 160-176. http://dx.doi.org/10.1108/JEAS-07-2015-0023

FareedMastan, P., Gameda, H., Rajeswari, P. \& Muhammed, S. (2015). The effectiveness of internal audit in improving organizational performance: Case study of Wollo University. Indian Journal of Applied Research, 5 (7), 547-550. doi: 10.15373/2249555X

Fernandes, J. (2000). Internal auditing in the next millennium. Auditwire Newsletter, January/February, 1-2.

Groff, M., Di Pietra, R. \& Sitar, A. (2016). Contemporary role of internal auditing in corporate governance. Dynamic Relationships Management Journal, 5 (1), 51-63. doi:10.17708/DRMJ.2016.v05no1a04

Habib, M. \& Jalloh, A. (2016). Internal control in tertiary institutions: Ensuring a continuous improvement in the educational system in Nigeria. International Journal of Information, Business and Management, 8 (1), 223-241.

Laviada, A., García, F. \& Arana, C. (2014). Retos de la auditoría interna en las universidades españolas. AECA, Espanha.

Ma'Ayan, Y. \& Carmeli, A. (2016). Internal audits as a source of ethical behavior, efficiency, and effectiveness in work units. Journal of Business Ethics, 137 (2), 347-363. doi: 10.1007/s10551-015-25610

Marçal, N. \& Marques, F. (2011). Manual de auditoria e controlo interno no sector público. Lisboa: Edições Sílabo.

Marques, M. \& Almeida, J. (2004). Auditoria no sector público: Um instrumento para a melhoria da gestão pública. Revista Contabilidade \& Finanças da Universidade de S. Paulo- Brasil, 35 (3), 84-95.

Mihret, D.G. \& Yismaw, A. W. (2007). Internal audit effectiveness: An Ethiopian public sector case study. Managerial Auditing Journal, 22(5), 470-484.

Monteiro, F. (1998). Auditoria interna (Dissertação de mestrado não publicada). Escola Superior de Economia, Instituto Superior de Contabilidade e Administração do Porto, Portugal.

Morais, G. (2003). La necessidade de la auditoría interna en el sector público en Portugal. Comunicação apresentada no XII Congresso da AECA.

Morais, G. \& Martins, I. (2007). Auditoria Interna - Função e processo. Lisboa: Áreas Editora.

Paço, I. (1997). O papel do auditor interno no apoio à gestão de topo. (Dissertação de mestrado não publicada). Escola Superior de Economia, Instituto Superior de Contabilidade e Administração do Porto, Portugal.

Rezaee, Z., Elmore, C. \& Szendi Z. (2001). Ethical behavior in higher educational institutions: The role of the code of conduct. Journal of Business Ethics, 30 (2), 171-183. doi:10.1023/A:1006423220775

Ribeiro, A. (2016). O papel da auditoria interna nas instituições públicas de ensino superior em Portugal continental - Uiversidades e politécnicos (Dissertação de mestrado não publicada). Instituto Superior de Contabilidade e Administração de Lisboa, Portugal.

Sá, E. (2008). Auditoria interna em Portugal ainda está longe da maturidade. Jornal de Negócios.

Skaerbaek, P. (2009). Public sector auditor identities in making efficiency auditable: The national audit office of Denmark as independent auditor and modernizer. Accounting, Organizations and Society, 34, 971-987. doi.org/10.1016/j.aos.2009.01.001

Tato, B. (1998). Auditoría Interna en Universidades: Situácion actual y perspectivas de futuro de la función de auditoria interna en la Universidad Española. Madrid: Instituto de Auditores Internos de España.

Zakaria, Z., Selvaraj, I. \& Zakaria, Z. (2006). Internal auditors: Their role in the institutions of higher education in Malaysia. Managerial Auditing Journal, 21 (9), 892-904. doi: 10.1108/02686900610704993 
SANDRINA MACHADO é mestre em Auditoria pelo Instituto Politécnico do Cávado e do Ave (IPCA) e inspetora tributária na delegação de Braga. Trabalhou durante vários anos no departamento financeiro de um politécnico, daí o interesse pelo tema em questão, o qual foi tratado, com maior profundidade na sua dissertação de mestrado. Endereço institucional: Rua do Eixo de Baixo, 4750-513 Lama, Barcelos, Portugal.

SARA SERRA é doutorada em Contabilidade pela Universidade do Minho. A sua linha de investigação é a auditoria financeira, tendo desenvolvido a tese de doutoramento sobre relatórios de auditoria. Professora Adjunta na Escola Superior de Gestão, do IPCA onde leciona a unidade curricular de Auditoria Financeira. Diretora do Mestrado em Auditoria e coordenadora da área disciplinar de Auditoria no Departamento de Contabilidade e Fiscalidade. Membro do Centro de Investigação em Contabilidade e Fiscalidade do IPCA. Secretária da Comissão de Prevenção da Corrupção do IPCA. Autora de várias publicações em revistas científicas e de trabalhos de investigação académica e aplicada, apresentados em congressos nacionais e internacionais. Referee de artigos revistas científicas nacionais e internacionais. Endereço institucional: Instituto Politécnico do Cávado e do Ave, Campus do IPCA, 4750810 Barcelos, Portugal.

PATRÍCIA GOMES é doutorada em Contabilidade e possui interesses de investigação na área de Contabilidade Pública, Contabilidade de Gestão e Performance no Setor Público. Vice-presidente do IPCA. Professora adjunta do Departamento de Contabilidade e Fiscalidade na Escola Superior de Gestão, do IPCA. Coordenadora da área disciplinar de Contabilidade Pública. Editora da revista científica Tékhne - Review of Applied Management Studies. Presidente do conselho científico e membro do Centro de Investigação em Contabilidade e Fiscalidade do IPCA. Referee de artigos em distintas revistas científicas internacionais. Autora de diversas publicações em revistas científicas e de trabalhos de investigação apresentados em vários congressos. Endereço Institucional: Instituto Politécnico do Cávado e do Ave, Campus do IPCA, 4750-810 Barcelos, Portugal.

Submetido em 10 agosto 2016

Aceite em 14 fevereiro 2017 